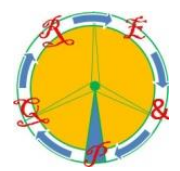

\title{
Design of an active pitch control for small horizontal-axis wind turbine
}

\author{
J. Vilà ${ }^{1}$, N. Luo ${ }^{1}$, L. Pacheco ${ }^{1}$, T. Pujol², J.R. Gonzalez ${ }^{2}$, I. Ferrer ${ }^{1}$, A. Massaguer ${ }^{2}$, E. Massaguer ${ }^{2}$ \\ ${ }^{1}$ Department of Electrical Engineering, Electronics and Automation, University of Girona, Campus Montilivi, 17003 \\ Girona (Spain) \\ ${ }^{2}$ Department of Mechanical Engineering and Industrial Construction, University of Girona, Campus Montilivi, 17003 \\ Girona (Spain)
}
Phone number:+0034 686750 724, e-mail: joaquim.vilab@udg.edu,ningsu.luo@udg.edu, lluis.pacheco@udg.edu, toni.pujol@udg.edu,joseramon.gonzalez@udg.edu, ines.ferrer@udg.edu, albert.massaguer@udg.edu, eduard.massaguer@udg.edu

\begin{abstract}
The installed power capacity from small wind turbines would rise in case of having higher efficiency values. The performance of these devices is very sensitive to wind conditions, especially to wind gusts and turbulence. Performance extracted from small-scale wind turbine datasheets show large variations of power output between turbulent and non-turbulent sites and often the installation in intermittent wind sites is discouraged. The use of blades with fixed positions is a clear drawback of small wind turbines. Here, we propose a design of a smart active pitch control to increase the energy generation of micro-wind turbines $(<5 \mathrm{kWp})$. The design consists of a simple mechanism that allows the rotation of the blades controlled by a low cost peripheral interface controller. The possibility to orientate the blades so as to maximise the power output at all wind conditions will increase the performance of this small wind turbines. The design is robust and economical, which will increase its potential adoptability rate by the end-user.
\end{abstract}

Key words. Active pith control, Wind energy, Small wind turbine.

\section{Introduction}

The current climate emergency clearly demands actions towards a change of the energy model, in which selfconsumption shall be promoted. Wind energy generation, however, is mainly obtained from farms of big wind turbines. The high technology applied to these large-scale devices leads to values of energy generation normalised by rotor area and to figures of the return of investment much more attractive than those for small wind turbines. A technological advance is required in order to favour the adoptability of small wind turbines for energy generation at micro scale.

The main technical disadvantage of small wind turbines corresponds to the use of fixed blades. Current state-ofthe-art large-scale horizontal wind turbines include active pitch control strategies to improve performance (see, e.g., [1-2]). However, micro- and mini-wind turbines use passive pitch control, essentially adopted for safety purposes. For these type of turbines, an active pitch control would allow to choose the most suitable blade orientation in terms of energy generation. Such a small wind turbine would even be suitable to work under intermittent and intense winds.

However, the commercial implementation of an active pitch control at small scales has discarded by its complexity and cost. Here, we have designed a very simple, robust and economical mechanism that allows to modify the pitch. Besides, the control of this mechanism is carried out by low cost electronic elements. So a feasible smart active pitch control system for micro- and mini-wind turbines is proposed.

\section{Commercial micro-wind turbine}

The design here described has been developed for an existing commercial micro-wind turbine, though it can be made extensive to any horizontal-axis model. Other type of wind turbines, like vertical-axis ones or horizontal-axis with crossflow runners as blades [3] are not analysed here.

The micro-wind turbine analysed is model M-300 of Guangmang. It is an horizontal-axis wind turbine with 6 blades of $0.82 \mathrm{~m}$ diameter and a rated power of $90 \mathrm{~W}$ at wind speed $12 \mathrm{~m} / \mathrm{s}$. This wind turbine has been tested in an open-circuit wind tunnel at our university facilities (see Fig. 1).

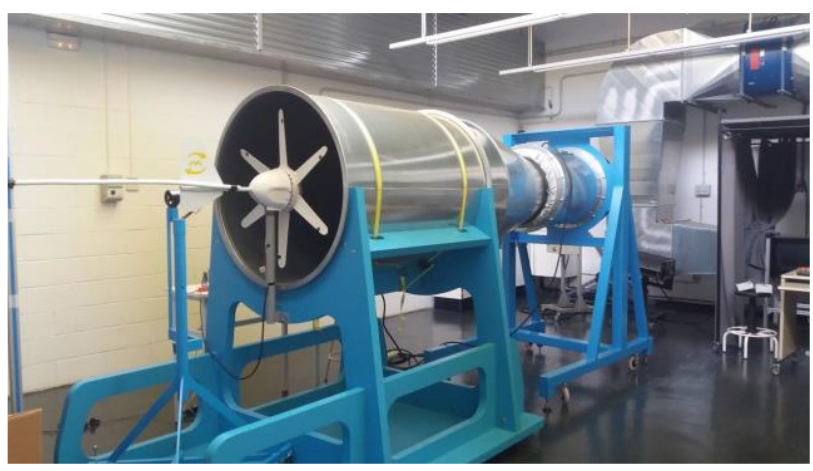

Fig. 1. Open-circuit wind tunnel at the Energies laboratory at the University of Girona with the commercial micro-wind turbine installed. 
The open-circuit wind tunnel uses a TGT/2 (Solé-Palau) fan of $18.5 \mathrm{~kW}$ with a nominal point of $34200 \mathrm{~m}^{3} / \mathrm{h}$ at $1066 \mathrm{~Pa}$ total pressure. A honeycomb is located inside the cylindrical section to straighten the flow. The fan is controlled by a variable speed drive Altivar Process 600 (Schneider Electric). At $50 \mathrm{~Hz}$, the wind speed at the exit of the wind tunnel may reach up to $15 \mathrm{~m} / \mathrm{s}$.

For safety purposes, the micro-wind turbine was tested up to wind speed values of $8 \mathrm{~m} / \mathrm{s}$. A rheostat was used to modify the external load in order to achieve the maximum output power for a fixed wind speed value. Results were compared with the manufacturer datasheet (Fig. 2).

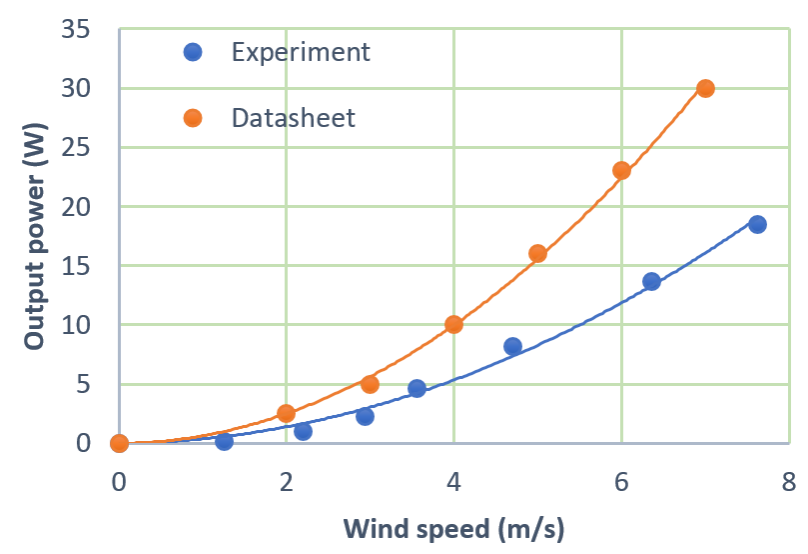

Fig. 2. Output power of the commercial micro-wind turbine as a function of the wind speed experimentally obtained and from the manufacturer datasheet.

Discrepancies between measured and expected values of output power may be due to the effect of turbulence on the incoming flow.

\section{Active pitch control design}

The assembly of the hub of the active pitch control mechanism is shown in Fig. 3. For simplicity, three blades have been used, as this is a common layout even at the micro-wind scale [4].

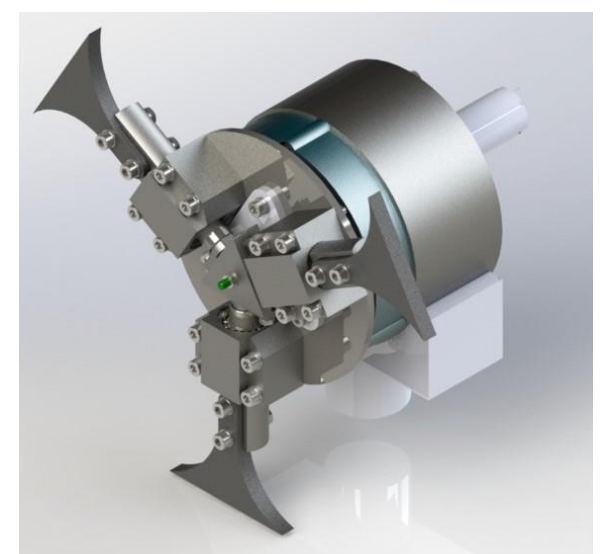

Fig. 3. Assembly of the hub of the active pitch control mechanism for the micro-wind turbine.

The objective of the mechanism is to transform a linear motion, through the axis of the system, into a rotating one that allows the turn of the blades. The mechanism designed to carry out this task is based on the Scotch Yoke mechanism. A central triangular prismatic element (1 in Fig. 4) has three slits in its rectangular faces that act as slider guides for the heads ( 2 in Fig. 4 ) of a rod ( 3 in Fig. 4) that connects with the base of the blade support (4 in Fig. 4). The triangular prismatic element (1) is linearly moved by a simple electric linear actuator whose axis is aligned with respect to the hub centre. This linear actuator is fixed in the wind turbine nacelle and, with a thrust ball bearing, it acts over a rod that crosses the hub centre finally screwed to the triangular prismatic element (see Fig. 5). With the dimensions of the hub, a linear motion of $20 \mathrm{~mm}$ is enough to rotate the blades $60^{\circ}$.

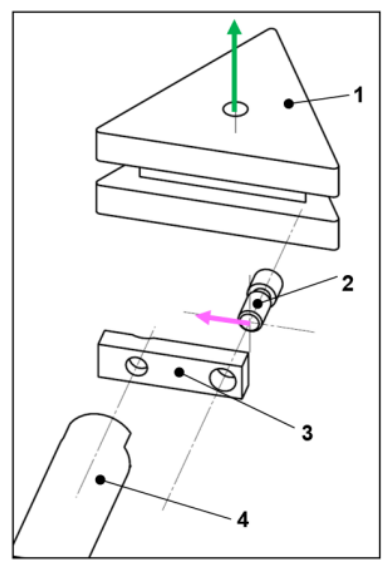

Fig. 4. Main elements of the Scotch Yoke type mechanism employed to transform the linear motion of (1) into a rotating motion of (4). See text for details.

Additional elements are needed to assure the functioning of the system, these being shown in Fig. 5. For example, wall bearings to allow the turn of each blade along its axis, sliding guides to assure the linear displacement of the triangular prismatic element, etc.

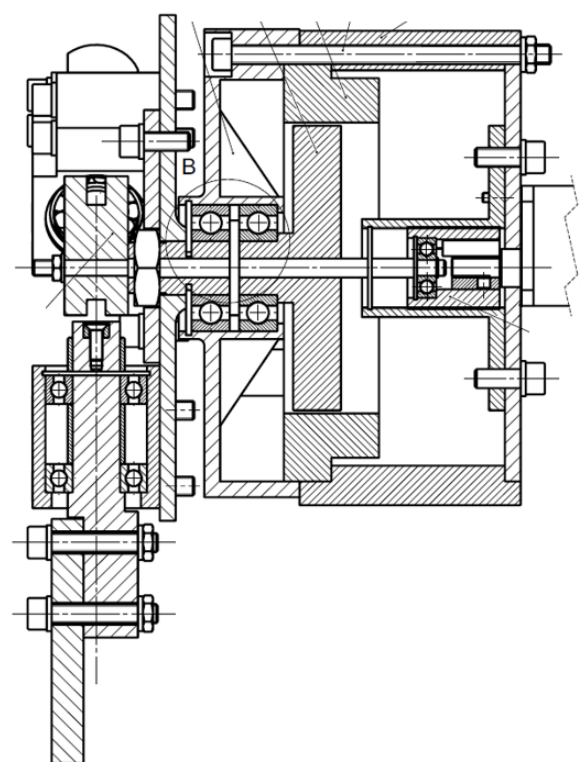

Fig. 5. Section view of the mechanism showing the main elements needed to complete the assembly. The triangular element (1) in Fig. 4 is that screwed at the end of the centreline rod at the left. 
Finally, the mechanism is controlled by the aid of several sensors and controllers, as described in Fig. 6. Sensor of wind speed, angular velocity of the turbine and power produced are required to define the position of the blade pitch angle. The optimum position as a function of the above variables will be determined from experimental data. The control of the system is carried out by economical 8 bits peripheral interface controller (PIC) Curiosity boards.

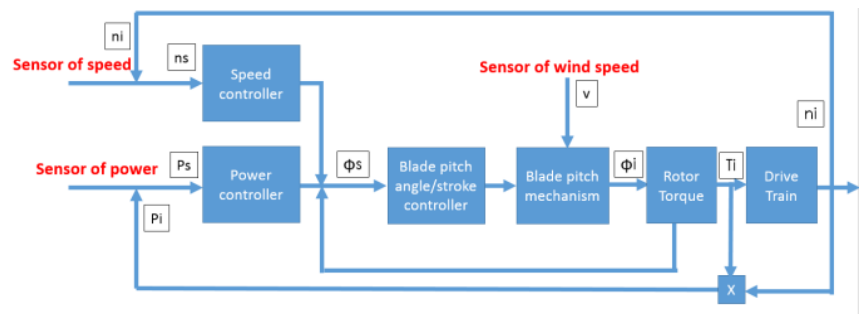

Fig. 6. Block diagram of the working mode for the electronics control of the active pitch control.

\section{Modified micro-wind turbine}

The non-standard elements described in the previous section were manufactured with the $3 \mathrm{D}$ printing technology of fused deposition modelling. This method turned out to be very cost-effective and the final assembly fulfilled with regard to the strength requirements of the laboratory test. Thus, the modified micro-wind turbine consisted of three blades, as seen in Fig. 7.

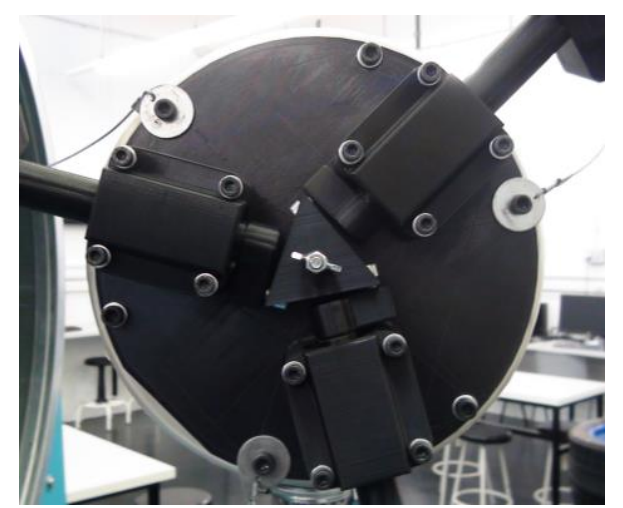

Fig. 7. Prototype of the active pitch control manufactured with $3 \mathrm{D}$ printing technology.

Note that the active pitch design increased the diameter of the turbine, now being $1.00 \mathrm{~m}$ (see Fig. 8). This diameter was slightly smaller than the inner diameter of the opencircuit wind tunnel. Therefore, wall effects were expected to reduce the wind velocity near the blade tip. Thus, the lower value of incoming wind velocity plus the reduction of the number of blades from six to three were expected to diminish the output power extracted from the modified micro-wind turbine in comparison with that obtained from the commercial device.

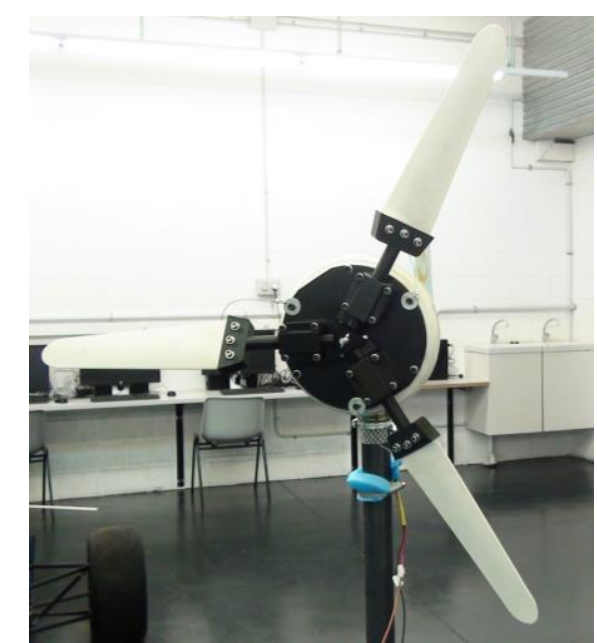

Fig. 8. Final assembly of the modified micro-wind turbine with the active pitch control mechanism.

However, our purpose was not to increase the output power. Instead, the objective of the present work was to determine the technical feasibility of the proposed design. The validation of this proof of concept will allow to replicate the design to mini-wind turbines (i.e., wind turbines of larger diameter and, therefore, with higher peak power capacity) that are originally built with the standard three blade design.

\section{Experimental results}

The experimental tests were carried out in the same facilities in which we tested the commercial unit (see Section 2 and Fig. 9). Here, voltage and current were continuously acquired by a National Instruments data acquisition system with 9215 and 9227 modules. Data were synchronized and processed with LabVIEW software that calculated output power. As in Section 2, a rheostat was used to modify the load resistance value.

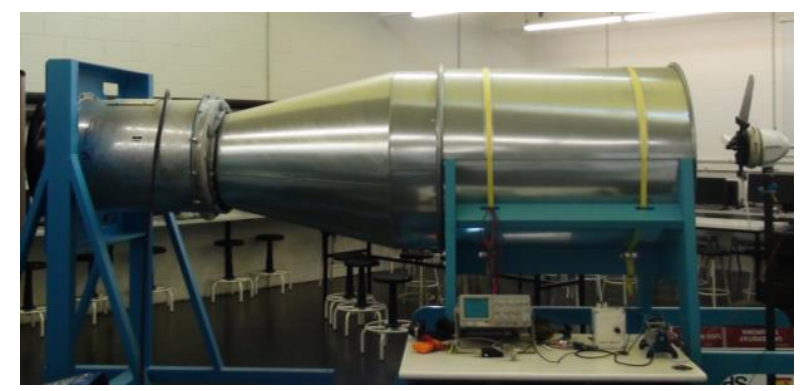

Fig. 9. Prototype installed at the exit of the open-circuit wind tunnel (right of the picture) ready to be tested.

We tested the performance of the micro-wind turbine for different values of the pitch angle and wind velocity. Figures 10 and 11 show the output power as a function of the load resistance obtained at mean inlet wind velocities of $6 \mathrm{~m} \mathrm{~s}^{-1}$ and $7 \mathrm{~m} \mathrm{~s}^{-1}$, respectively. 


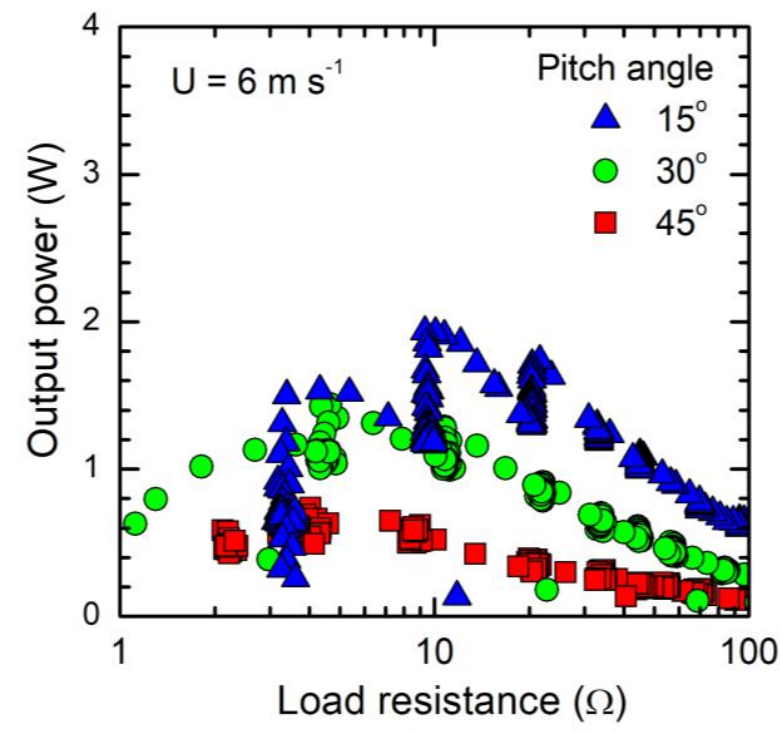

Fig. 10. Output power as a function of load resistance for different values of pitch angle. Inlet mean wind velocity equal to $6 \mathrm{~m} \mathrm{~s}^{-1}$.

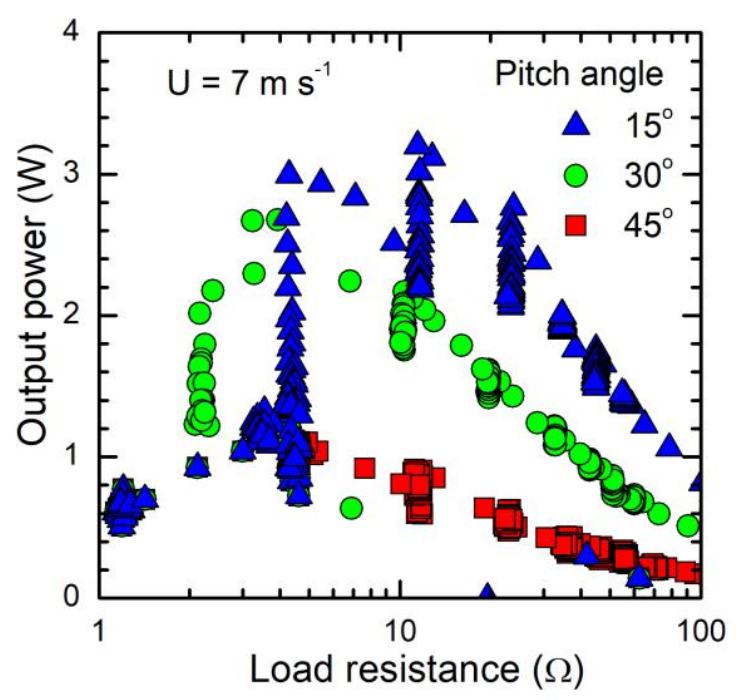

Fig. 11. Output power as a function of load resistance for different values of pitch angle. Inlet mean wind velocity equal to $7 \mathrm{~m} \mathrm{~s}^{-1}$.

From Figures 10 and 11 we clearly observe that the pitch angle has a strong influence on the extracted output power. A $15^{\circ}$ variation (pitch angle from $15^{\circ}$ to $30^{\circ}$ ) slightly decreases the performance $\left(-26 \%\right.$ for $U=6 \mathrm{~m} \mathrm{~s}^{-1} ;-16 \%$ for $\mathrm{U}=7 \mathrm{~m} \mathrm{~s}^{-1}$ ). However, a further $15^{\circ}$ variation (pitch angle up to $45^{\circ}$ ) dramatically reduces the maximum output power $\left(-49 \%\right.$ and $-56 \%$ for $\mathrm{U}=6 \mathrm{~m} \mathrm{~s}^{-1}$ and $7 \mathrm{~m} \mathrm{~s}^{-1}$, respectively). It is very remarkable that the change of maximum output power when changing the pitch angle from $15^{\circ}$ to $30^{\circ}$ angle is not so relevant for the case with higher wind speed $\left(\mathrm{U}=7 \mathrm{~m} \mathrm{~s}^{-1}\right)$. In this case, the difference is only $16 \%$, indicating that, as wind speed increases, the maximum output power may be attained when blades have a higher pitch angle value.

We also observe that the maximum output power at different pitch angles is achieved at different load resistance values. In comparison with the commercial model, the maximum values achieved at pitch angle $15^{\circ}$ for $\mathrm{U}=7 \mathrm{~m} \mathrm{~s}^{-1}$ is $3.2 \mathrm{~W}$ only, whereas the commercial unit was almost $15 \mathrm{~W}$ (see Fig. 2). As explained in Section 4, the reduction in the number of blades and the increase in size diameter have implied the decline in the performance.

All in all, the results indicate the interest of modifying the blade pitch angle even for small wind turbines and validate the technical feasibility of the proposed design of an active pitch control system.

\section{Conclusions}

We have designed an active pitch control for a horizontal-axis micro-wind turbine with the purposes of increasing its performance and of making the device more robust against gust and high winds. The mechanism is based on a Scoth Yoke, being simple, robust and economical. The smart control of the system is also carried out through simple and economical sensors and boards.

A proof of concept of the mechanism has been manufactured with 3D printing technology. The assembly has been tested in an open-circuit wind tunnel.

Results show the high influence of the pitch angle on the micro-wind turbine performance. Output power data obtained at different wind speed values and pitch angles suggest that an active pitch control may extract more energy than that obtained with fixed blades. Therefore, this technology applied to mini-wind turbines appears as a feasible candidate to improve the performance from current devices.

\section{Acknowledgement}

This work has been cofunded by the European Union through the European Regional Development Funds (FEDER). It has also been cofunded by the Secretaria d'Universitats i Recerca del Departament d'Empresa i Coneixement de la Generalitat de Catalunya through the Agència de Gestió d'Ajuts Universitaris i de Recerca under contract Ajut Llavor - 2019 LLAV 00003.

\section{References}

[1] Vidal, Y.; Acho, L.; Luo, N.; Zapateiro, M.; Pozo, F. Power control design for variable-speed wind turbines. Energies, 2012, 5, 3033-3050.

[2] Pozo, F.; Vidal, Y.; Acho, L.; Luo, N.; Zapateiro, M. Power regulation of wind turbines using torque and pitch control. American Control Conference, Washington DC, USA. June 1719, 2013.

[3] Pujol, T.; Massaguer, A.; Massaguer, E.; Montoro, L.; Comamala, M. Net power coefficient of vertical and horizontal wind turbines with crossflow runners. Energies, 2018, 11, 110. [4] Airx X Marine Specifications. Southwest Windpower, Inc. 2002. Flagstaff (Arizona) USA. 